\title{
LAPM: A LIQUIDITY-BASED ASSET PRICING MODEL
}

\author{
Bengt Holmström \\ Jean Tirole
}

\author{
Working Paper 6673 \\ http://www.nber.org/papers/w6673
NATIONAL BUREAU OF ECONOMIC RESEARCH
1050 Massachusetts Avenue
Cambridge, MA 02138
August 1998

The authors are grateful to Olivier Blanchard, Seven Busar, Mathias Dewatripont, Douglas Diamond, Peter Diamond, Arvind Krishnamurthy, Jean-Charles Rochet, Stephen Ross, Jeremy Stein, and Xavier Vives for helpful discussions. This research was supported by a grant from the National Science Foundation. Any opinions expressed are those of the author and not those of the National Bureau of Economic Research.

C 1998 by Bengt Holmström and Jean Tirole. All rights reserved. Short sections of text, not to exceed two paragraphs, may be quoted without explicit permission provided that full credit, including $\mathbb{C}$ notice, is given to the source. 
LAPM: A Liquidity-based Asset Pricing Model

Bengt Holmström and Jean Tirole

NBER Working Paper No. 6673

August 1998

JEL No. G12

\section{ABSTRACT}

The intertemporal CAPM predicts that an asset's price is equal to the expectation of the product of the asset's payoff and a representative consumer's intertemporal marginal rate of substitution. This paper develops an alternative approach to asset pricing based on industrial and financial corporations' desire to hoard liquidity to fulfill future cash needs. Our corporate finance approach to market finance suggests new determinants of asset prices such as the distribution of wealth within the corporate sector and between the corporate sector and the consumers. Also, leverage ratios, capital adequacy requirements, and the composition of savings affect the corporate demand for liquid assets and thereby interest rates.

The paper first sets up a general model of corporate demand for liquid assets, and obtains an explicit formula for the associated liquidity permia. It then derives some implications of corporate liquidity demand for the equity premium puzzle, for the yield curve, and for the state-contingent volatility of asset prices. Finally, the paper looks at some macroeconomic implications of the theory. It shows that government may be able to boost aggregate liquidity and enhance economic efficiency by promoting job and asset price stability. On the liability side, long-term deposits and equity investments, which depend on the consumers' endogenously determined liquidity needs, contribute to creating a feedback effect between employment prospects and equity-like investments. On the asset side, orderly sales of real estate by liquidity-squeezed institutions may generate a Pareto improvement.

Bengt Holmström

Department of Economics E52-271d

MIT

Cambridge, MA 02139

and NBER

bengt@mit.edu
Jean Tirole

Institute d'Economie Industrielle

Univeriste des Sciences Socilaes de Toulouse Place Anatole France

31042 Toulouse Cedex, France 


\section{Introduction}

Starting with the capital asset pricing model (CAPM, derived by Sharpe 1964, Lintner 1965 and Mossin 1966), market finance has emphasized the role of consumers' time preference and risk aversion in the determination of asset prices. The intertemporal consumption-based asset pricing model (e.g., Rubinstein 1976, Lucas 1978, Breeden 1979, Harrison-Kreps 1979, Cox et al. 1985, Hansen-Jagannathan 1991) predicts that an asset's current price is equal to the expectation, conditioned on current information, of the product of the asset's payoff and a representative consumer's intertemporal marginal rate of substitution (IMRS). While fundamental, this dominant paradigm for pricing assets has some well-recognized shortcomings (see below), and there is clearly scope for alternative and complementary approaches. This paper begins developing one such approach based on aggregate liquidity considerations. ${ }^{1}$

Our starting point is that the productive and financial spheres of the economy have autonomous demands for financial assets and that their valuations for these assets are often disconnected from the representative consumer's. Corporate demand for financial assets is driven by the desire to hoard liquidity in order to fulfill

\footnotetext{
${ }^{1}$ Liquidity in this paper does not refer to the ease with which assets can be resold. While transaction costs (stamp duties, brokerage fees, bid-ask spread) have an important impact on the pricing of individual assets, their implications for aggregate liquidity have not yet been elucidated.
} 
future cash needs. In contrast to the logic of traditional asset pricing models based on perfect markets, corporations are unable to raise funds on the capital market up to the level of their expected income, and hence the corporate sector will use financial assets as a cushion against liquidity shocks (Holmström-Tirole, 1996, 1998). Financial assets that can serve as cushions will command liquidity premia. $^{2}$

There is substantial evidence that firms and banks hold liquid assets as a partial or full guarantee of future credit availability (see, e.g., Crane 1973 and Harrington 1987). Companies protect themselves against future credit rationing by holding securities and, especially, by securing credit lines and loan commitments with banks and other financial institutions. Lines of credit cover working capital needs and back up commercial paper sales. Commitments provide longterm insurance through revolving credits, which often have an option that allows the company to convert the credit into a term loan at maturity, and through back-up facilities that protect a firm against the risk of being unable to roll over its outstanding commercial paper. Companies pay a price for these insurance

\footnotetext{
${ }^{2}$ This theme relates to Hicks' notion of "liquidity preference" for monetary instruments and other close substitutes. He defines "reserve assets" as assets that are held to facilitate adjustments to changes in economic conditions and thus not only for their yield. For an historical perspective on the developments following Keynes (1930)'s and Hicks' contributions to liquidity preference, see the entries by A. Cramp and C. Panico in the New Palgrave Dictionary of Money and Finance.
} 
services through upfront commitment fees and costly requirements to maintain compensatory balances.

Turning to the supply side, the provision of liquidity is a key activity of the banking sector. Banks occur a nonnegligible credit risk, as the financial condition of companies may deteriorate by the time they utilize their credit facilities. Furthermore, the rate of utilization of credit facilities (which varies substantially over time) is not independent across time. ${ }^{3}$ Credit use tends to increase when money is tight, forcing banks to scramble for liquidity in order to meet demand. Banks themselves purchase insurance against unfavorable events. On the asset side, they hoard low-yielding securities such as Treasury notes and high-grade corporate securities. On the liability side, they issue long-term securities to avoid relying too much on short-term retail deposits. Within the banking sector, liquidity needs are managed through extensive interbank funds markets.

A corporate finance approach to asset pricing has several potential benefits. First, it enlarges the set of determinants of asset prices. In contrast to consumption-based asset pricing models, in which the net supply of financial assets is irrelevant for asset prices because they are determined exclusively by

\footnotetext{
${ }^{3}$ Calomiris (1989) argues on the basis of a survey of US market participants that the Central Bank is sometimes forced to inject market liquidity during credit crises because of bank loan commitments.
} 
real variables, our model features a feedback effect from the supply of assets to the real allocations. The corporate sector is not a veil and the distribution of wealth within the corporate sector, and between the corporate sector and the consumer sector matters; in particular, the capital adequacy requirements imposed on banks, insurance companies and securities firms, and the current leverage of financial and nonfinancial institutions affect corporate demand for financial assets and thereby asset prices. Second, government influences the aggregate amount of liquidity through interventions such as open market operations, discounting, prudential rules and deposit insurance (see Stein 1996) and this impacts liquidity premia and asset prices. Consumption-based asset pricing models, provided they exhibit a form of Ricardian equivalence, have little to say about the impact of such policies.

Because the consumption-based asset pricing model is entirely driven by consumers' intertemporal marginal rates of substitution (IMRS), it has several empirical limitations. ${ }^{4}$ First, it tends to underpredict both equity premia (see, e.g., Mehra-Prescott 1985) and Treasury bill discounts. ${ }^{5}$ Second, changes in marginal

\footnotetext{
${ }^{4}$ We view these facts less as critiques of the theory than as indicators of the need to complement it with liquidity considerations.

${ }^{5}$ As Aiyagari-Gertler (1991) note, "reasonably parametrized versions [of the intertemporal asset pricing model] tend to predict too low a risk premium and too high a risk-free rate," and do not account for the 7 percent secular average annual real return on stocks and 1 percent secular average return on Treasury bills. A number of papers have used nonseparable preferences to address the equity premium puzzle (with mixed success; see Ferson 1995 and Shiller 1989 for
} 
rates of substitution (discount rates) induce asset prices to covary. But as Shiller (1989, p. 346-8) notes, "prices of other speculative assets, such as bonds, land, or housing, do not show movements that correspond very much at all to movements in stock prices."

Third, the consumption-based asset pricing model does not properly account for the facts that the yield curve is on average upward sloping (at least up to medium term bonds), that government intervention affects its slope, and that long-term bonds feature substantial price volatility (see, e.g., Shiller 1989, chapter 12.) It is often argued that the term premium results from the price risk of longterm bonds. However, this argument is not supported by a complete market model like CAPM, because price risk per se only entails a reshuffling of wealth among investors and involves no aggregate risk that would deliver a premium.

Fourth, the consumption-based asset pricing model has not guided the important advances in Autoregressive Conditional Heteroskedasticity (ARCH) models. ${ }^{6}$ ARCH models and their generalizations allow the covariance matrix of innovations to be state-contingent in order to reflect observations by Mandelbrot (1963),

reviews), while the other puzzle - the low risk-free rate - has been largely ignored as pointed out by Weil (1989) and Aiyagari-Gertler.

${ }^{6}$ See, e.g., Bollerslev et al. (1992), Engle et al. (1990) and Ghysels-Harvey-Renault (1996). ARCH methods, though, have been used on an ad hoc basis (for example by allowing the betas in a CAPM model to change over time) in order to improve the fit of the intertemporal asset pricing model. 
Fama (1965) and Black (1976) that variances and covariances of asset prices change through time and that volatility tends to be clustered across time and across assets.

A proper treatment of these empirical discrepancies of the consumption-based asset pricing model lies outside the limited scope of this exploratory paper. Let us briefly indicate though how the liquidity approach could help to bridge the gap between theory and empirics.

First, concerning the equity premium puzzle we find that Treasuries and other high-grade securities offer better insurance against shortfalls in corporate earnings and other liquidity needs than do stocks. To highlight this point, we deliberately assume that consumers are risk neutral, so that stocks and bonds alike would trade at par in the standard model; yet in our model bonds command a liquidity premium and trade at a discount relative to stocks.

Second, by assuming risk-neutral consumers, we eliminate consumer IMRS's as drivers of asset price movements. Instead prices will be responding to changes in corporate IMRS's, which in turn are influenced by corporate demand for liquidity. The theoretical implications are different. For instance, unlike the consumption CAPM, our model implies that an increase in the supply of liquidity drives bond prices down at the same time as stock prices go up. In empirical work, 
we also believe that the corporate sector may offer a better measure of changes in the marginal purchaser's IMRS than do corresponding attempts to study partial participation among consumers. (For a recent effort, see Vissing-Jorgensen, 1997).

Third, in our model the yield curve is determined by the value of various maturities as liquidity buffers, and is also affected by the availability of other assets and by the anticipated institutional liquidity needs. This generates richer patterns for the yield curve than in a consumption-based theory.

Fourth, in our model price volatility is state contingent and exhibits serial correlation. Under some conditions, the price volatility of fixed-income securities covaries negatively with the price level (as Black 1976 notes, volatilities, which covary across assets, go up when stock prices go down.) Intuitively, fixed-income securities embody an option-like liquidity service. When there is a high probability of a liquidity shortage, the option is "in the money" and its price will be sensitive to news about the future. When the probability of liquidity shortage is sufficiently low, the price of the option goes to zero and will not respond much to news.

The paper is organized as follows. Section 2 illustrates the determination of liquidity premia through a simple example. Section 3 sets up a general model of 
corporate liquidity demand. This model shows how departures from the ArrowDebreu paradigm generates liquidity premia. Sections 4 and 5 demonstrate that the liquidity approach delivers interesting insights for the volatility of asset prices and for the yield curve. The final section 6 studies two examples with endogenous date- 1 asset prices to illustrate the possibility of multiple equilibria and the role that policy measures can play in ensuring that the better equilibrium gets selected. The first example (section 6.1) suggests that unemployment insurance can provide liquidity that supports long-term investments. The second example (section 6.2) illustrates the problem with real assets as sources of liquidity: such assets have a low value precisely when the aggregate need for liquidity is high.

\section{Liquidity premium: an example}

There are three periods, $t=0,1,2$, one good, and a continuum (of mass 1 ) of identical entrepreneurs, each with one project. Entrepreneurs are risk neutral and do not discount the future. They have no endowment at date 0 and must turn to investors in order to defray the fixed date- 0 set up cost, $I$, of their project. At date 1 , the project generates a random verifiable income $x$. The realization

of $x$ is the same for all entrepreneurs and so there is aggregate uncertainty. The distribution $G(x)$ of $x$ is continuous on $[0, \infty)$, with density $g(x)$ and a mean 
greater than $I$.

At date 1 , the firm reinvests a monetary amount $y \geq 0$, which at date 2 generates a private benefit $b y-\frac{y^{2}}{2}$ for the entrepreneur, with $b>1$. This private benefit cannot be recouped by the investors; it is nonpledgeable.

The only noncorporate financial asset is a Treasury bond. ${ }^{7}$ At date 0 the government issues $\bar{L}$ bonds that mature at date 1 and yield one unit of the good in every state. The date- 0 price of a bond is $q$. The repayment of the Treasury bond is financed through taxes on consumers.

Consumers (investors) are also risk neutral and do not discount the future. They value consumption stream $\left(c_{0}, c_{1}, c_{2}\right)$ at $c_{0}+c_{1}+c_{2}$. A key assumption is that consumers cannot individually commit to provide entrepreneurs with funds at date 1 , because they cannot borrow against their future income. ${ }^{8}$ The consumers' preferences imply that they will hold only assets whose expected rate of return is nonnegative. This implies in particular that $q \geq 1$. If $q>1$, consumers hold no Treasury bonds and we will refer to $q-1$ as the liquidity premium. The liquidity

\footnotetext{
${ }^{7}$ The only feature of a Treasury bond that is going to be relevant for our analysis is that its payoff is exogenous. It could equally well be the output of some similarly exogenous asset like land.

${ }^{8}$ One can rationalize this assumption by assuming that individuals can credibly claim that they have no date-1 income. The tax authority in contrast has information about individual earnings. An alternative interpretation is that unborn generations of consumers cannot make commitments, but the government can do so on their behalf. See our 1998 paper for a more extensive discussion of the theoretical foundations and for the empirical validity of these assumptions.
} 
premium can be strictly positive, because consumers cannot commit to date-1 payments and hence cannot short-sell assets.

A contract between a representative entrepreneur and the investors specifies a quantity $L$ of Treasury bonds to be held by the firm and an income contingent reinvestment policy $y(x)$. Because consumers cannot commit to provide more funds at date 1 , the reinvestment policy must satisfy

$$
y(x) \leq x+L .
$$

For notational simplicity, we will assume that investors receive $x+L-y$. It is easy to show that this is indeed the case if the expected date- 1 income is not too large. ${ }^{9}$ Investors expect a nonnegative rate of return, and so

$$
E_{0}[x-I-y(x)-(q-1) L] \geq 0,
$$

where is a date- 0 expectation, and expectations are taken with respect to the random variable $x$. A competitive capital market guarantees that (2) is satisfied with equality. Because investors break even, entrepreneurs receive the social surplus associated with their activity. Figure 1 summarizes the timing.

\footnotetext{
${ }^{9}$ When expected income is very large, that is, when firms generate substantial liquidity themselves, the results below apply with $\mu=1$.
} 
Figure 1 here.

The optimal contract between a representative entrepreneur and the investors maximizes the social surplus generated by the entrepreneurial activity,

$$
E_{0}\left[b y(x)-\frac{(y(x))^{2}}{2}\right]
$$

subject to constraints (1) and (2). Letting $\mu>1$ denote the shadow price of constraint (2), this optimization amounts to

$$
\max _{\{y(\cdot), L\}}\left\{E_{0}\left[b y(x)-\frac{(y(x))^{2}}{2}+\mu[x-I-y(x)-(q-1) L]\right\}\right.
$$

subject to the liquidity constraint

$$
y(x) \leq x+L \quad \text { for all } x .
$$

For fixed $L$, the solution of the unconstrained program is

$$
y^{*}=b-\mu,
$$

and the solution to the constrained program is 


$$
y(x)=\min \left(y^{*}, x+L\right),
$$

so firms are liquidity constrained in low-income states.

Let us turn to the date- 0 choice of liquidity. From our previous characterization, $L$ is chosen to maximize

$$
\begin{aligned}
& \int_{0}^{y^{*}-L}\left[b(x+L)-\frac{(x+L)^{2}}{2}-\mu(I+q L)\right] g(x) d x \\
& +\int_{y^{*}-L}^{\infty}\left[b y^{*}-\frac{\left(y^{*}\right)^{2}}{2}-\mu\left[I+y^{*}+(q-1) L-x\right]\right] g(x) d x .
\end{aligned}
$$

Assuming $L>0$ the first-order condition is

$$
q-1=\int_{0}^{y^{*}-L}\left[\frac{b-(x+L)}{\mu}-1\right] g(x) d x .
$$

Let

$$
m(x) \equiv\left\{\begin{array}{cc}
\frac{b-(x+L)}{\mu}-1 & \text { for } x \leq y^{*}-L \\
0 & \text { for } x \geq y^{*}-L .
\end{array}\right.
$$

Then 


$$
q-1=E_{0}[m(x)]
$$

The liquidity premium is equal to the expected marginal value of the liquidity service. In states of liquidity-shortage $\left(x<y^{*}-L\right)$, an extra unit of liquidity allows the firm to increase its reinvestment by 1 and the private benefit by $b-$ $(x+L)$. This marginal private benefit, expressed in monetary terms, is equal to $[b-(x+L)] / \mu$. The increase in reinvestment has monetary cost 1 . This yields the expression for the liquidity premium (6).

We have looked for an equilibrium $\{q, \mu\}$ in which Treasury bonds command a liquidity premium. Such an equilibrium satisfies the break-even constraint (2) (with equality) and the asset pricing equation (5), for $L=\bar{L}$ (because $q>1$, investors do not hold Treasury bonds), and for the optimal reinvestment policy $y(\cdot)$ defined by (3) and (4). If the solution to this system yields $q \leq 1$, then Treasury bonds command no liquidity premium $(q=1)$; that is, even if liquidity is free, firms may not hold all available liquid claims.

It is easy to show that i) there exists an $L^{*}$ such that $q>1$ if and only if $\bar{L}<L^{*}$; and ii) the value of the marginal liquidity service $m(\cdot)$ and the price of liquid claims $q$ are monotonically decreasing in $\bar{L}$. These results are illustrated in figure 2, where $m_{\bar{L}}(\cdot)$ denotes the marginal liquidity service for bond supply $\bar{L}$. 
When $\bar{L}=\bar{L}_{3}>L^{*}$, the economy has surplus liquidity, and there is no liquidity premium. ${ }^{10}$ Hence, bond prices are low. The cases $\bar{L}=\bar{L}_{1}$ or $\bar{L}_{2}$ depict the interesting case of scarce liquidity.

Figure 2 here.

Remark: Note that the value of liquidity $m(x)$ is linear in $x$ in this example. Linearity requires that the date- 2 payoff be nonverifiable, that is, the payoff is purely a private benefit. Alternatively, the date- 2 payoff could be verifiable but not fully pledgeable as in Holmström-Tirole (1998), for instance, because moral hazard problems require the entrepreneur to keep a stake in the final payoff. Under mild conditions, the value of liquidity $m(x)$ would then differ from that depicted in figure 2 only in that the decreasing part would be convex rather than linear. $^{11}$

\footnotetext{
${ }^{10}$ To endogenize $\bar{L}$ we would have to introduce a cost of issuing Treasury securities, such as a deadweight loss of taxing consumers when debt is retired. See our 1998 paper for more detail.

${ }^{11}$ The assumptions are: The reinvestment $y$ produces date-2 income $f(y)$ with probability $p$ and 0 with probability $1-p$. The entrepreneur can work $\left(p=p_{H}\right)$ or shirk $\left(p=p_{L}=p_{H}-\Delta p\right)$. Shirking generates a private benefit $B f(y)$. Letting $\rho_{0} \equiv p_{H}[1-(B / \Delta p)]$ we have $m^{\prime \prime}(x) \geq 0$ if $3 \rho_{0}\left(f^{\prime \prime}\right)^{2}+\left(1-\rho_{0}\left(f^{\prime}\right) f^{\prime \prime \prime} \geq 0\right.$.
} 


\section{LAPM}

Let us now develop a more general framework. There are three periods, $t=0,1,2$. At date 1 , a state of nature $\omega$ in $\Omega$ is revealed to all economic agents. There is a further resolution of uncertainty at date 2, but in our risk neutral framework, only date- 1 expectations matter so we need not specify the date- 2 random events. The state of nature $\omega$ may include the date- 1 profits of the various industries in the corporate sector (as in the example above), their date-1 reinvestment needs (as in our 1998 paper ), news about the prudential requirements or government policy, or signal/prospects about date-2 revenues. ${ }^{12}$

- Investors. As in the example, and in order to highlight the departure from the canonical asset pricing model, we assume that investors are risk neutral and have an exogenously given discount rate, normalized at zero. That is, investors value consumption stream $\left(c_{0}, c_{1}, c_{2}\right)$ at $c_{0}+c_{1}+c_{2}$. One could assume more generally that investors have endogenously determined and possibly stochastic discount factors. Similarly, the implicit assumption that investors face no liquidity needs could be relaxed (see section 6.1).

- Noncorporate claims. At date 0 , there are $K$ noncorporate assets, $k=$

\footnotetext{
${ }^{12}$ For a more general representation of consumer preferences, could also include shocks to investors' rate of time preference.
} 
$1, \ldots, K$ such as Treasury securities or real estate. The return on asset $k$ at date 1 , that is, the date- 1 dividend plus the date- 1 price, is equal to $\theta_{k}=\theta_{k}(\omega) \geq 0$. The mean return on each asset is normalized to be one: $E_{0}\left[\theta_{k}(\omega)\right]=1$, where $E_{t}[\cdot]$ denotes the expectation of a variable conditional on the information available at date $t$. Let $\bar{L}_{k}$ denote the supply of asset $k$. At date 0 , asset $k$ trades at price $q_{k}$ per unit, where $q_{k} \geq 1$ from the nature of consumer preferences. The liquidity premium on asset $k$ is equal to $q_{k}-1$.

Note that the returns $\left\{\theta_{k}(\omega)\right\}$ are exogenously given. In section 6 we will analyze two examples with endogenous returns. Note also that claims $k=$ $1, \ldots, K$ do not include claims on the corporate sector (shares, bonds, deposits, CDs,...). We will later provide valuation formulae for these.

- Corporate sector. Our model treats the productive and financial sectors as a single, aggregated entity, called the "corporate sector." The Appendix provides sufficient conditions validating this approach. The corporate sector invests at dates 0 and 1 and receives proceeds at dates 1 and 2 . Let $I$ denote the corporate sector's date-0 gross investment (or vector of gross investments) in productive (illiquid) assets. Its date- 0 net investment, $N(I)$, is equal to the difference between the gross investment and the productive sector's capital contribution at date 0 (in the example above, $N(I)=I$ since the entrepreneurs had no initial 
wealth).

The net investment $N(I)$ is only part of the investors' date- 0 contribution to the corporate sector. The corporate sector also purchases noncorporate assets $\left\{L_{k}\right\}_{k=1, \ldots, K}$ at date 0 . The investors' date- 0 outlay is thus

$$
N(I)+\sum_{k} q_{k} L_{k}
$$

In equilibrium all claims commanding a liquidity premium $\left(q_{k}>1\right)$ must be held by the corporate sector $\left(L_{k}=\bar{L}_{k}\right)$, because consumers are risk neutral.

At date 1 , the corporate sector selects a decision $d=d(\omega)$ from a feasible set $D(\omega, L(\omega))$, where $L(\omega)$ is the net liquidity available to the corporate sector in state $\omega$. The decision vector $d$ includes all real decisions within the corporate sector such as reinvestments and production decisions for every firm. Implicitly, it also includes reallocations of liquidity among firms, required to support these real decisions. This presumes fully efficient financial contracting between firms in the corporate sector. For instance, scarce liquidity may be allocated efficiently at date 1 by financial intermediaries (see Holmström-Tirole 1998 for more detail). If the corporate sector does not pay insiders (entrepreneurs) anything at date 1 (see below), then 


$$
L(\omega)=\sum_{k} \theta_{k}(\omega) L_{k}
$$

Recall that investors cannot commit to bringing in new funds at date 1 beyond the amount that is held in liquid assets $L(\omega)$.

\section{Assumption 1 (opportunity-enhancing liquidity)}

For all $\omega, L_{1}$ and $L_{2}$ : if $L_{1}<L_{2}$, then $D\left(\omega, L_{1}\right) \subseteq D\left(\omega, L_{2}\right)$.

In general, an increase in liquid reserves strictly enlarges the set of feasible corporate policies when financial markets are imperfect. For instance, in our earlier example, $\omega=x$, and $D(\omega, L)=\{y \mid y \leq x+L\}$.

For a given state $\omega$, let $R(I, \omega, d)$ denote the total expected intertemporal (date 1 plus date 2) payoff from illiquid corporate assets (in the example, $R=$

$\left.x+\left[b y-\frac{y^{2}}{2}\right]-y\right) . \quad R$ includes pledgeable and nonpledgeable returns on illiquid assets, but excludes the return $\sum_{k} \theta_{k}(\omega) L_{k}$ on noncorporate securities. Let $r(I, \omega, d)$ denote the corresponding pledgeable income from illiquid assets, that is the expected intertemporal income that can be returned to investors (in the example, $r(I, \omega, d)=x-y)$. Accounting for noncorporate assets purchased at date 0 , the corporate sector can return at most 


$$
r(I, \omega, d(\omega))+\sum_{k} \theta_{k}(\omega) L_{k}
$$

to investors. Let

$$
B(I, \omega, d(\omega)) \equiv R(I, \omega, d(\omega))-r(I, \omega, d(\omega))
$$

denote the nonpledgeable portion of income. The fact that $B>0$ is critical for generating a corporate demand for liquidity in our model.

Let $t(\omega)$ denote the amount of pledgeable income that is paid out (at date 1) to corporate insiders (entrepreneurs) in state $\omega$. The net liquidity available for reinvestment in state $\omega$ is then $\sum_{k} \theta_{k}(\omega) L_{k}-t(\omega)$.

The corporate sector solves:

$$
\max _{\{I, L, d(\cdot), t(\cdot)\}}\left\{E_{0}[R(I, \omega, d(\omega))]-I-\sum_{k}\left(q_{k}-1\right) L_{k}\right\}
$$

subject to the investors' break-even condition:

$$
E_{0}[r(I, \omega, d(\omega))-t(\omega)]+\sum_{k} L_{k} \geq N(I)+\sum_{k} q_{k} L_{k},
$$


and to date-1 decisions being feasible:

$$
d(\omega) \in D\left(\omega, \sum_{k} \theta_{k}(\omega) L_{k}-t(\omega)\right)
$$

Assuming that the investors' break-even constraint is binding, this program can be rewritten as

$$
\max _{\{I, L, d(\cdot)\}}\left\{E_{0}[B(I, \omega, d(\omega))+t(\omega)]+N(I)-I\right\}
$$

subject to (7) and (8).

Let $\mu \geq 1$ denote the shadow price of the break-even constraint in this latter program, and define

$$
\left.m(\omega) \equiv \frac{d}{d L}\left[\max _{d \in D(\omega, L)}\left\{\frac{B(I, \omega, d)+\mu r(I, \omega, d)}{\mu}\right\}\right]\right|_{L=\bar{L}(\omega)}
$$

as the marginal liquidity service (expressed in terms of pledgeable income) in state $\omega$ assuming that the available liquidity is $L(\omega) \equiv \sum_{k} \theta_{k}(\omega) \bar{L}_{k}$. Assumption 1 implies that $m(\omega) \geq 0$ for all $\omega$.

Assume that there exists at least one state of nature in which there is excess liquidity, that is, in which the decision $d(\omega)$ is in the interior of the feasible decision set $D$. This is a mild assumption and is satisfied in all our examples. It implies 
(see the Appendix for more detail) that pledgeable income is never redistributed to the corporate sector in states of liquidity shortage $(t(\omega)=0$ if $m(\omega)>0)$, and so the available liquidity in equation (9) is appropriately defined. ${ }^{13}$

Optimization with respect to $L_{k}$, at equilibrium market prices, $x$ yields ${ }^{14}$

$$
q_{k}-1=E_{0}\left[\theta_{k}(\omega) m(\omega)\right]
$$

or, equivalently

$$
q_{k}=E_{0}\left[\theta_{k}(\omega)[1+m(\omega)]\right]
$$

Like risk premia, liquidity premia are determined by a covariance formula, but this time involving the intertemproal marginal rate of substitution $1+m(\omega)$ of the corporate sector. An asset's liquidity premium is high when it delivers income in states in which liquidity has a high value for the corporate sector.

For completeness, we can finally introduce external claims on the corporate sector (shares, bonds, etc.). Let $\bar{L}_{j}$ be the date-0 supply of claim $j$ paying $\theta_{j}(\omega)$

\footnotetext{
${ }^{13}$ By the same reasoning, we will be able to ignore state-contingent liquidity withdrawals $t(\cdot)$ in the other programs in the paper.

${ }^{14}$ Note that we assume that the corporate sector as a whole takes prices as given. Price taking presumes that there is competition for assets within the corporate sector. In section 6.2 we consider cartel behavior.
} 
at date 1 in state of nature $\omega$. The set of external claims, $j=1, \ldots, J$, must satisfy

$$
\sum_{j} \theta_{j}(\omega) \bar{L}_{j}=r(I, \omega, d(\omega))+\sum_{k} \theta_{k}(\omega) L_{k}-t(\omega)
$$

The date-0 prices of such claims, $\left\{q_{j}\right\}_{j=1, \ldots, J}$, will be given by

$$
q_{j}-1=E_{0}\left[\theta_{j}(\omega) m(\omega)\right]
$$

Single state of liquidity shortage.

Suppose liquidity is scarce in a single state, $\omega_{H}$, which has probability $f_{H}$. According to (10), the liquidity premium on asset $k$ is then proportional to the asset's payoff conditional on the occurrence of the bad state:

$$
q_{k}-1=f_{H} \theta_{k}\left(\omega_{H}\right) m_{H} .
$$

This linear relationship yields the following

$$
\frac{q_{k}-1}{q_{\ell}-1}=\frac{\theta_{k}\left(\omega_{H}\right)}{\theta_{\ell}\left(\omega_{H}\right)}
$$

which implies a one-factor model of liquidity premia. We can take the bond price 
as the single factor. That is, if $q_{b}$ is the date- 0 price of a bond delivering one unit of good at date 1 , the liquidity premium on asset $k$ perfectly covaries with the liquidity premium on the bond: ${ }^{15}$

$$
q_{k}-1=\theta_{k}\left(\omega_{H}\right)\left(q_{b}-1\right)
$$

With more than one state of scarce liquidity, (10) results in a multi-factor model where the factors can be chosen as the liquidity premia of any subset of assets that spans the states in which liquidity shortages occur.

The Arrow-Debreu economy.

Assets do not command a liquidity premium under the following additional assumptions:

Assumption 3 (fully pledgeable income): For all $I, \omega, d, R(I, \omega, d)=r(I, \omega, d)$. Assumption 3 corresponds to the absence of agency costs and private (nonpledgeable) benefits.

Assumption 4 (efficient contracting): For all $\omega$ and all $L$,

\footnotetext{
${ }^{15}$ This assumes that the asset's payoff $\theta_{k}$ does not vary conditional on $\omega_{H}$. If it varies, then $\theta_{k}\left(\omega_{H}\right)$ should be replaced by $E\left(\theta_{k} \mid \omega_{H}\right)$ in the formula below.
} 


$$
\max _{d \in D(\omega, L)} r(I, \omega, d)=\max _{d \in D(\omega, 0)} r(I, \omega, d)
$$

According to this assumption, liquidity is valueless when it comes to maximizing pledgeable income. To understand its role, suppose that the corporate sector hoards no liquidity, and so $L=0$. Suppose that in state of nature $\omega$, there exists $L$ such that

$$
r\left(I, \omega, d^{*}(\omega, L)\right)>r\left(I, \omega, d^{*}(\omega, 0)\right)
$$

where $d^{*}(\omega, L)$ denotes the maximizing pledgeable income decision in state $\omega$ given liquidity $L$. The corporate sector could at date 1 borrow $L$ and pledge $r\left(I, \omega, d^{*}(\omega, L)\right)-L+L>r\left(I, \omega, d^{*}(\omega, 0)\right)$, a contradiction.

Given Assumptions 3 and $4, m(\omega)$ is equal to 0 for all $\omega$, since

$$
\begin{aligned}
& \max _{d \in D(\omega, L(\omega))}\left\{\frac{B(I, \omega, d)+\mu r(I, \omega, d)}{\mu}\right\} \\
= & \max _{d \in D(\omega, L(\omega))}\{r(I, \omega, d)\} \\
= & \max _{d \in D(\omega, 0)}\{r(I, \omega, d)\} .
\end{aligned}
$$


Thus, all liquidity premia are zero in an Arrow-Debreu economy.

\section{Information filtering and volatility}

As we noted in the introduction, many recent advances in empirical finance were motivated by the observation that conditional variances and covariances change over time. It is well-known, for instance, that volatility is clustered, that asset volatilities (stock volatilities, bond volatilities across maturities) move together, and that stock volatility increases with bad news. ${ }^{16}$ This section does not attempt to provide a general theory of the impact of liquidity premia on volatility. Its only goal is to suggest that a liquidity-based asset pricing model has the potential to deliver interesting insights into state-contingent volatilities.

\subsection{Example}

Let us first return to the example of section 2. In this example with nonverifiable second-period income, the liquidity benefit of the Treasury bond is a put option, since $m(x)$ decreases linearly with first-period income $x$ until it hits zero. We also observed that with verifiable second-period income and under some mild regularity conditions, $m(x)$ decreases and is convex until it hits zero.

\footnotetext{
${ }^{16}$ Black (1976) attributes the last fact to the "leverage effect" (equity, which is a residual, moves more when the debt-equity ratio increases.) However, this leverage effect does not seem to account for clustering of volatility and comovements between stock and bond volatilities.
} 
Suppose now that news arrives intermittently between dates 0 and 1 containing information about the realization of $x$ at date 1 . Specifically, suppose that there are $N$ news dates between 0 and 1 (the first distinct from date 0 and the Nth equal to date 1). Assume further that the realization of $x$ is given by either an additive or a multiplicative process

$$
\begin{aligned}
x & =x_{0}+\sum_{m=1}^{N} \eta_{m} \\
& \equiv x_{n}+\sum_{m=n+1}^{N} \eta_{m} \quad \text { for all } n
\end{aligned}
$$

or

$$
\begin{aligned}
x & =x_{0}\left[\times_{m=1}^{N} \eta_{m}\right] \\
& \equiv x_{n}\left[\times_{m=n+1}^{N} \eta_{m}\right] \quad \text { for all } n,
\end{aligned}
$$

where the increments $\eta_{m}$ are independently distributed.

The early accrual of information about the state $\omega$ will have no impact on the optimal decision rule $d(\cdot)$ and hence no retrading of financial contracts occurs between dates 0 and 1 . Yet, we can price Treasury bonds by arbitrage at each 
subdate $n$. Contingent on the available information at subdate $n$, summarized by $x_{n}$,

$$
q_{n}\left(x_{n}\right)-1=E_{n}\left[m(x) \mid x_{n}\right]
$$

where $E_{n}[\cdot \mid \cdot]$ denotes the conditional expectation given information at subdate $n$.

(Formula (14) is derived formally for the general framework in section 4.2.)

It can be shown that, provided $m^{\prime}<0$ and $m^{\prime \prime} \geq 0$, for either the additive (13a) or the multiplicative process $(13 \mathrm{~b})$, we have ${ }^{17}$

$$
\frac{d}{d x_{n}}\left[E_{n}\left[\left[q_{n+1}\left(x_{n+1}\right)-q_{n}\left(x_{n}\right)\right]^{2} \mid x_{n}\right]\right] \leq 0
$$

In words, the volatility of the Treasury bond price is state contingent, and the higher the volatility, the worse the prospects for the economy. The simple logic is that volatility is high when the option is in the money and low when it is out of the money.

Remark: In the example with nonverifiable second-period income, the BlackSholes formula yields an explicit formula for the volatility of the bond price if the

\footnotetext{
${ }^{17}$ The proof for the multiplicative process follows from that for the additive process by taking logs in (13b). Indeed if $m(\cdot)$ is decreasing and convex, $m\left(e^{\hat{x}}\right)$ is also decreasing and convex in $\hat{x}$, where $\hat{x} \equiv \log x$.
} 
process is a continuous time geometric Brownian motion.

\subsection{General LAPM}

Let us investigate more generally the impact of news about the state of nature in the LAPM framework of section 3. As in the example, we assume that there are subdates $n=1, \ldots, N$ between dates 0 and 1 , at which informative signals accrue about the date- 1 state of nature $\omega$. Thus, the market's information about the state of nature at date 1 gets refined over time. Let $\sigma_{n}$ denote the market's information at subdate $n$ with $\sigma_{N}=\omega$. We let $E\left[\cdot \mid \sigma_{n}\right]$ denote the subdate- $n$ expectation of a variable conditional on the information available at time $n$. The corporate sector purchases quantity $L_{k}$ of liquid asset $k$ at date 0 , and can afterwards reconfigure its portfolio so that it holds (information contingent) quantity $L_{k}\left(\sigma_{n}\right)$ at subdate $n$. Asset $k$ 's equilibrium price given information $\sigma_{n}$ is denoted $q_{k}\left(\sigma_{n}\right)$.

Consider the problem of maximizing the corporate sector's expected payoff subject to the investors' date- 0 break-even condition and date- 1 decisions being feasible: ${ }^{18}$

$$
\max _{\{I, L, L(\cdot), d(\cdot)\}}\left\{E_{0}[B(I, \omega, d(\omega))]+N(I)-I\right\}
$$

\footnotetext{
${ }^{18}$ The maximand of this program is the same as in (3) upon substitution of the budget constraint.
} 
subject to

$$
\begin{aligned}
E_{0}[r(I, \omega, d(\omega))] \geq & N(I)+\sum_{k} q_{k} L_{k} \\
& +E_{0}\left[\sum_{k} \sum_{n=1}^{N} q_{k}\left(\sigma_{n}\right)\left[L_{k}\left(\sigma_{n}\right)-L_{k}\left(\sigma_{n-1}\right)\right]\right] \\
& -E_{0}\left[\sum_{k} \theta_{k}(\omega) L_{k}(\omega)\right],
\end{aligned}
$$

and

$$
d(\omega) \in D\left(\omega, \sum_{k} \theta_{k}(\omega) L_{k}(\omega)\right)
$$

A few comments are in order. First, $\sigma$. is measurable with respect to $\omega$, and so the set of feasible decisions is indeed a well-defined function of the state of nature. Second, the date- 0 contract with investors specifies some portfolio adjustment at each date. We ignore the possibility that contemplated portfolio adjustments may require a net contribution by investors at subdate $n\left(\sum_{k} q_{k}\left(\sigma_{n}\right)\left[L_{k}\left(\sigma_{n}\right)-L_{k}\left(\sigma_{n-1}\right)\right]>0\right)$. While such a contribution could occur if the portfolio adjustment raised the investors' wealth conditional on $\sigma_{n}$, it would not occur if the adjustment reduced it, since the investors would be unwilling ex post to bring in new funds, and 
they cannot ex ante commit to do so. However, if in equilibrium $q_{k}>1$, then $L_{k}\left(\sigma_{n}\right)=\bar{L}_{k}$ for all $\sigma_{n}$ is an optimal policy, and so investors do not have to contribute at intermediate dates. The fictitious subdate- $n$ reshuffling of liquid assets between the corporate sector and the rest of the economy is, as in Lucas (1978), only used to price financial assets at an intermediate date.

As before, we let $\mu$ be the multiplier of the break- even constraint in (16) and define the marginal liquidity service $m(\omega)$ as in (9). Taking first-order conditions we find that for each liquid asset $k \in\{1, \ldots, K\}$ and for each subdate $n \in\{1, \ldots, N-1\}:$

$$
\begin{aligned}
q_{k} & =1+E_{0}\left[\theta_{k}(\omega) m(\omega)\right], \\
q_{k} & =E_{0}\left[q_{k}\left(\sigma_{n}\right)\right]
\end{aligned}
$$

and

$$
q_{k}\left(\sigma_{n}\right)=E_{n}\left[\theta_{k}(\omega)[1+m(\omega)] \mid \sigma_{n}\right]
$$

Asset prices (or liquidity premia) form a martingale because there is no liquidity service within the periods where news arrives. Only at the last subdate (date 1) 
will the liquidity premium disappear and hence the martingale property fail. Note that the martingale condition reflects the fact that firms are indifferent regarding the timing of the purchase of liquidity, as long as the purchase is made before the final date. The martingale condition stems from arbitrage within the investors' budget constraint.

Define a "generalized fixed-income security," as one with expected return unchanged as news accrues, that is,

$$
E_{n}\left[\theta_{k}(\omega) \mid \sigma_{n}\right]=1, \quad \text { for all } n \text { and } \sigma_{n}
$$

For simplicity, we focus on these securities in the rest of this section. We can then write (18) as

$$
q_{k}\left(\sigma_{n}\right)-1=E_{n}\left[\theta_{k}(\omega) m(\omega) \mid \sigma_{n}\right]
$$

Condition (19) rules out volatility stemming from news about the assets' dividends. Such volatility must be added (with a correction depending on the covariance with the innovations about liquidity needs) to our price formulae when expected payoffs change over time.

Asset volatility in the case of a single state of liquidity shortage. 
Assuming that there is a single state $\left(\right.$ state $\left.\omega_{H}\right)$ of liquidity shortage, let $f_{H}\left(\sigma_{n}\right)$ denote the posterior probability of the bad state of nature at subdate $n$, conditional on the information available at that subdate. Let

$$
\Im\left(\sigma_{n}\right)=E_{n}\left\{\left[\frac{f_{H}\left(\sigma_{n+1}\right)-f_{H}\left(\sigma_{n}\right)}{f_{H}\left(\sigma_{n}\right)}\right]^{2} \mid \sigma_{n}\right\}
$$

denote the relative variance of the posterior probability. $\Im\left(\sigma_{n}\right)$ is a measure of the informativeness of the signal accruing at subdate $n+1$.

Note, from (20), that the ratio formula (12) continues to apply with $q_{k}\left(\sigma_{n}\right)$ in place of $q_{k}$. So at subdate $n$ and for any two assets $k$ and $\ell$,

$$
\frac{q_{k}\left(\sigma_{n}\right)-1}{q_{\ell}\left(\sigma_{n}\right)-1}=\frac{\theta_{k}\left(\omega_{H}\right)}{\theta_{\ell}\left(\omega_{H}\right)} \equiv \lambda_{k, \ell}
$$

Under the (strong) assumption of just one liquidity constrained state, and with a government bond on the market, all assets with constant expected dividend are priced according to a linear formula involving the liquidity premium on that bond. This is a close analog to the CAPM.

Contingent volatilities and clustering.

Let $V_{k}$ and $v_{k}$ denote the absolute and relative volatilities of the price of asset $k$ conditional on information $\sigma_{n}$ : 


$$
V_{k}\left(\sigma_{n}\right)=E_{n}\left[\left[q_{k}\left(\sigma_{n+1}\right)-q_{k}\left(\sigma_{n}\right)\right]^{2} \mid \sigma_{n}\right]
$$

and

$$
v_{k}\left(\sigma_{n}\right)=E_{n}\left[\left[\frac{q_{k}\left(\sigma_{n+1}\right)-q_{k}\left(\sigma_{n}\right)}{q_{k}\left(\sigma_{n}\right)}\right]^{2} \mid \sigma_{n}\right] .
$$

With only one liquidity-constrained state, the price in information state $\sigma_{n}$ of an asset $k$ with constant expected dividend is, as we have seen,

$$
q_{k}\left(\sigma_{n}\right)-1=f_{H}\left(\sigma_{n}\right) \theta_{k}\left(\omega_{H}\right) m_{H} .
$$

This immediately yields our main formulae:

$$
\begin{gathered}
V_{k}\left(\sigma_{n}\right)=\Im\left(\sigma_{n}\right)\left[q_{k}\left(\sigma_{n}\right)-1\right]^{2}, \\
V_{k}\left(\sigma_{n}\right)=\Im\left(\sigma_{n}\right)\left[\frac{q_{k}\left(\sigma_{n}\right)-1}{q_{k}\left(\sigma_{n}\right)}\right]^{2}, \\
V_{k}\left(\sigma_{n}\right)=\lambda_{k, \ell} V_{\ell}\left(\sigma_{n}\right),
\end{gathered}
$$




$$
v_{k}\left(\sigma_{n}\right)=\lambda_{k, \ell} v_{\ell}\left(\sigma_{n}\right)
$$

Equations (24) and (25) state that, in absolute as well as relative terms, the volatility of an asset's price is proportional to the square of the asset's liquidity premium. Because prices move slowly, an immediate corollary is that an asset's price volatility is serially correlated; that is, we predict temporal clustering of an asset's volatility.

Equations (26) and (27) state that the volatility ratio of two assets is constant over time. Assets volatilities move together because they are driven by the same news concerning the likelihood of a liquidity shortage.

Returning to formulae (24) and (25), we note that volatility is also proportional to the informativeness $\Im\left(\sigma_{n}\right)$ of the signal accruing at subdate $n+1$. With two states, this informativeness measure is generally state-dependent, rendering these results less useful. To illustrate a case with constant informativeness, suppose that information accrues according to a Bernoulli process: At each subdate $n$, with probability $\lambda \in(0,1)$, the market learns that the economy will not be in the bad state of nature $\left(f_{H}\left(\sigma_{n}\right)=0\right)$. If that happens, the economy becomes an "Arrow-Debreu economy," in which assets command no liquidity premium and hence $q_{k}\left(\sigma_{m}\right)=1$ for all $m \geq n$. In this absorbing state, informativeness may 
be taken equal to 0 . With probability $1-\lambda$, the economy remains an "LAPM economy" and $f_{H}\left(\sigma_{n}\right)=(1-\lambda)^{N-n}$. A simple computation shows that in this example:

$$
\Im\left(\sigma_{n}\right)=\frac{\lambda}{1-\lambda}
$$

There is price volatility as long as the liquidity premium is strictly positive. If news accrues that the economy will be replete with liquidity, the liquidity premium goes to zero as will the volatility of prices for all assets with constant expected payoffs.

\section{The yield curve}

\subsection{The slope of the yield curve and price risk}

The theoretical and econometric research on the term structure of interest rates traditionally views the corporate sector as a veil in the sense that the yield curve is not influenced by asset liability management (ALM). Many believe, however, that corporate liquidity demand affects the term structure. First, while debt markets are segmented, there is enough substitutability across maturities to induce

long and short rates to move up and down together (Culbertson, 1957). Dura- 
tion analysis, stripping activities and more generally financial engineering and innovation (answering the question of "who is the natural investor for the new security?") provide indirect evidence for segmentation. A number of factors such as fiscal incentives, the creation of pension funds, new accounting and prudential rules for intermediaries, and the leverage of the real and financial sectors are likely to affect the demand for maturities differentially, thereby influencing the term structure. Second, the maturity structure of government debt seems to play a role in the determination of the term structure, a fact that is not accounted for in Ricardian consumption-based asset pricing models. ${ }^{19}$

The yield curve is most commonly upward sloping, although it may occasionally be hump-shaped or inverted or even have an inverted-hump-shape (see, Campbell et al., 1996, Campbell, 1995, and Stigum, 1990). The substantially higher yield on 6 month- than on 1 month- $T$ bills has been labelled a "term premium puzzle." 20 It is often argued that an upward-sloping yield curve reflects the riskiness of longer maturities. Investors, so the story goes, demand a discount as compensation for price risk (which presumably is correlated with consumption if the standard model applies). This argument is based on an analogy with CAPM.

\footnotetext{
${ }^{19}$ For example, the Clinton administration has begun to shorten the average maturity of government debt to take advantage of lower short term yields.

${ }^{20}$ There are a number of other stylized facts: short yields move more than long yields; longterm bonds are highly volatile; and high yield spreads tend to precede decreases in long rates. Also the yield curve tends to be flatter when money is tight.
} 
It would be worthwhile, though, to provide a precise definition of the notion of "price risk." CAPM is about the coupon risk of assets. Coupon risk relates to uncertainty about dividends, or, more generally (to encompass uncertainty about preferences and endowments), to uncertainty about the marginal utility of dividends.

Price risk may stem from coupon risk, but it need not. Consider an intertemporal Arrow-Debreu endowment economy (as in Lucas 1978). In this economy, early release of information about future endowments is irrelevant in that it affects neither the real allocation nor the date- 0 price of claims on future endowments. On the other hand, release of information affects asset prices, inducing price risk. In an Arrow-Debreu economy, the date-0 price of claims on date- 2 endowments can be entirely unrelated to the variance of their date- 1 price (or to the covariance of price and some measure of aggregate uncertainty). Price risk per se is not an aggregate risk and thus need not affect asset prices.

Returning to the yield curve, Treasury bonds are basically default-free. Uncertainty about the rate of inflation, however, creates a coupon risk (for nominal bonds), which in turn affects prices. Inflation uncertainty clearly plays an important part in explaining the price risk of long-term bonds. But for short-term bonds the connection is less obvious. A bond that matures in less than a year 
is quite insensitive to inflation, at least directly. Indirectly, swings in the price of long-term bonds will of course influence short-term prices as long as maturities are partially substitutable. Even so, inflation-induced price risk can hardly explain the term premium puzzle.

Our point is to caution against drawing hasty conclusions about the link between price risk and the slope of the yield curve. A theoretical justification based on the standard CAPM logic cannot be provided, because in a complete market, price risk stemming from early information release will not carry any risk premium. This opens the door for alternative theoretical approaches to analyzing the yield curve. Our liquidity-based asset pricing model offers one possibility.

\subsection{Long-term bonds and the Hirshleifer effect}

In order to obtain some preliminary insights into the effects of liquidity on the term structure, let us again return to the example of section $2 .{ }^{21}$ Assume that the government at date 0 issues two types of bonds: $\bar{\ell}$ short-term bonds yielding one unit of the good at date 1 , and $\bar{L}$ (zero coupon) long-term bonds yielding $\theta$ units of the good at date 2. We allow for a coupon risk on long-term bonds, so let $\theta$ be a random variable with support $[0, \infty)$, density $h(\theta)$, cumulative distribution

\footnotetext{
${ }^{21}$ The analysis in this section is valid for any concave private benefit function.
} 
$H(\theta)$, and mean $E_{0}(\theta)=1$. As discussed above, $\theta$ can be interpreted as the date-2 price of money in terms of the good. The case of a deterministic inflation rate (which can be normalized to 0 ) corresponds to a spike in the distribution at $\theta=1$. We let $q$ and $Q$ denote the date- 0 prices of short- and long-term bonds. A long-term price premium corresponds to $q>Q$. Treasury bonds are the only liquid assets in the economy

In the example the date- 1 income $x$ is assumed to be perfectly correlated across firms. Let $g(x)$ and $G(x)$ denote the density and the cumulative distribution of income $x$. Assume that $\theta$ and $x$ are independent. In this economy, firms have no liquidity demand past date $1 .{ }^{22}$ Therefore, if there is no coupon risk $(\theta \equiv 1)$ or if there is no signal about the realization of $\theta$ before date 2 (so that there is a coupon risk, but no price risk at date 1), short-term and long-term bonds will be perfect substitutes and so $q=Q$. Suppose instead that the realization of $\theta$ is learned at date 1 . Now the price at which long-term bonds can be disposed of at date 1 , namely $\theta$, will vary. The coupon risk in this case induces a price risk.

Let $\ell$ and $L$ denote the number of short-term and long-term bonds purchased at date 0 by the corporate sector (in equilibrium, $\ell=\bar{\ell}$ if $q>1$ and $L=\bar{L}$ if $Q>1$.) The corporate sector solves

\footnotetext{
${ }^{22}$ This example is meant to illustrate a situation in which most of the liquidity is expected to be employed in the short run with long-term liquidity needs expected to be less pressing.
} 


$$
\max _{\{y(\cdot), \ell, L\}} E_{0}\left[b y(x)-\frac{(y(x))^{2}}{2}\right]
$$

s.t.

$$
E_{0}[x-I-y(x)-(q-1) \ell-(Q-1) L] \geq 0,
$$

and

$$
y(x) \leq x+\ell+\theta L \quad \text { for all } x .
$$

Let $\mu$ again denote the shadow cost of the investors' break-even constraint and let $y *=b-\mu$ denote the optimal unconstrained reinvestment level. Because $\ell=\bar{\ell}$ and $L=\bar{L}$ in equilibrium, equilibrium prices are characterized by:

$$
\begin{gathered}
q-1=\int_{0}^{\infty}\left[\int_{0}^{y *-\bar{\ell}-\theta \bar{L}}\left[\frac{b-(x+\bar{\ell}+\theta \bar{L})}{\mu}-1\right] g(x) d x\right] h(\theta) d \theta, \\
Q-1=\int_{0}^{\infty} \theta\left[\int_{0}^{y *-\bar{\ell}-\theta \bar{L}}\left[\frac{b-(x+\bar{\ell}+\theta \bar{L})}{\mu}-1\right] g(x) d x\right] h(\theta) d \theta .
\end{gathered}
$$


Denote the inside integrals in (28) and (29) by $z(\theta)$. It is easily verified that $z^{\prime}(\theta)<0$. Consequently,

$$
Q-1=E_{0}[\theta z(\theta)]<E_{0}[\theta] E_{0}[z(\theta)]=E_{0}[z(\theta)]=q-1
$$

The price differential between short- and long-term bonds here reflects a more general theme, namely that the liquidity approach to asset pricing implies a skewness in risk tolerance. What matters is the average coupon delivered in states of pressing liquidity need. The term premium stems from the fact that a short-term bond delivers 1 unit for sure in such states, while the date- 1 price of the longterm bond is negatively correlated with the marginal liquidity service $m(\cdot)$. The difference $q-Q$ measures the cost of hedging against the date-1 coupon/price risk on long-term bonds.

Non neutrality of price risk. Long-term bonds would provide a better liquidity service (namely the same service as short-term bonds) if there were no uncertainty about inflation or if no information about $\theta$ arrived at date 1 . This contrasts with an Arrow-Debreu economy, in which early arrival of information never is harmful. Such information has no impact in an endowment economy, and may generate social gains in a production economy because of improved decision making. Our model features a logic similar to Hirshleifer's (1971) idea that early information 
arrival may make agents worse off. Our model differs from Hirshleifer's, in that in his model information arrives before entrepreneurs and investors sign a contract. In our model it is the investors' inability to commit to bringing in funds at date 1 that constrains contracting and makes information leakage problematic. Put differently, investors cannot offer entrepreneurs insurance against variations in the price of long-term bonds. If the price of long-term bonds is negatively correlated with the firm's liquidity needs, as is the case here, long-term bonds become inferior liquidity buffers to short-term bonds.

Neutrality of pure price risk. Let us follow section 4 and assume that news about the date- 1 state accrues between date 0 and date 1 , at subdates $n=1, \ldots, N$; that is, at each subdate $n$, a signal $\sigma_{n}$ accrues that is informative about the date- 1 income and/or the coupon on the long-term bond. Then, the prices of shortand long-term bonds adjust from their date- 0 values $q$ and $Q$ to $q\left(\sigma_{n}\right)$ and $Q\left(\sigma_{n}\right)$. This price risk, however, has no impact on the date-0 prices $q$ and $Q$ which remain given by (28) and (29), since the corporate sector in equilibrium does not reshuffle its portfolio of liquid assets (this is the point made earlier that capital gains and losses on financial assets have offsetting effects.) In other words, price risk has no impact on the slope of the date-0 yield curve. On the other hand, news affects the slope of the yield curve at subdates. 
The yield curve may be upward sloping even in the absence of a coupon risk. In the absence of any coupon risk, $q=Q$. Let $i_{1}$ and $i_{2}$ denote the yields on short and long bonds at date 0 . These yields are negative in our model because the consumers' rate of time preference is normalized to zero. We have

$$
q=Q=\frac{1}{1+i_{1}}=\frac{1}{\left(1+i_{2}\right)^{2}}
$$

and so

$$
i_{1}=\frac{1}{q}-1<i_{2}=\frac{1}{\sqrt{Q}}-1
$$

This trivial example makes the point that riskiness of long-term bonds is not a necessary condition for the existence of a term premium. The yield curve can be upward-sloping, as here, simply because the corporate sector has no liquidity demand at date 2. This suggests that an upward slope is associated with relatively more pressing short-term liquidity needs, perhaps because the firm has less flexibility to adjust plans in the short term.

Other shapes of the yield curve. Suppose the income shock $x$ and reinvestment decision $y$ take place at date 2 , and the private benefit accrues at date 3 . Investments and financing still occur at date 0 . In this temporal extension of the 
model, date 1 is just a "dummy date," at which nothing happens. Suppose that the government still issues short-term bonds (maturing at date 1) and long-term bonds (maturing at dates 2 and 3). Short-term bonds offer no liquidity service and so $q=1$. Hence the short rate (equal to 0 ) exceeds the long rates, and we obtain an inverted yield curve.

This example makes the simple point that if the corporate sector does not expect to face liquidity needs in the short run, it does not pay a liquidity premium on short-term securities, and so they will yield more than long-term securities.

\section{Coordination failures in the creation and utilization of liquidity}

The analysis so far has assumed that the corporate sector makes efficient use of liquidity, but has no control over the aggregate supply. This is a reasonable assumption for assets such as Treasuries whose (i) supply $\bar{L}_{k}$ and (ii) statecontingent payoffs $\theta_{k}(\omega)$ can be considered exogenous. We now show by means of simple examples that the corporate sector's date-1 policy can affect aggregate liquidity in ways that are relevant for policy making. In the first example, the aggregate supply of liquidity can be directly influenced by the corporate sector. In the second example, the effect is indirect as asset prices depend on corporate decisions. In both cases, coordination failures may occur despite the fact that 
we continue to assume that the corporate sector makes optimal use of its liquid assets.

Throughout this section, there are no bonds or other forms of external liquidity.

\subsection{Precarious employment relationships hurt long-term savings and equity investments}

In this section only, assume that consumers, whose mass is 1, must consume

some "subsistence level" (food, education, housing, etc.) at the intermediate date. That is, we replace the utility

$$
c_{0}+c_{1}+c_{2}
$$

from consumption flow $\left(c_{0}, c_{1}, c_{2}\right)$ by the utility

$$
c_{0}+u\left(c_{1}\right)+c_{2},
$$

where 


$$
u\left(c_{1}\right)= \begin{cases}c_{1} & \text { if } c_{1} \geq \underline{c}_{1}>0 \\ -\infty & \text { otherwise. }\end{cases}
$$

Consumers thus care about the consumption path as well as its level.

The representative firm's investment cost at date 0 is normalized at $I=1$. As before, assume that consumers have enough of the nonstorable good at date 0 to help finance the initial investment $I$. The firm's income at date-1 has two possible values: high income $x_{H}$ with probability $f_{H}$, and low income $x_{L}$ with probability $f_{L}=1-f_{H}$, where

$$
x_{H}>x_{L}=\underline{c}_{1} .
$$

Continuation at date 1 requires, in addition to entrepreneurs, one worker / consumer per unit of investment. A worker must be paid an efficiency wage $w$, where $^{23}$

$$
w>\underline{c}_{1} .
$$

\footnotetext{
${ }^{23}$ We can invoke the standard efficiency wage model: The worker receives some private benefit $w$ when shirking and none when working. Suppose for simplicity that the work/shirk decision is perfectly verified ex post, that the worker is protected by limited liability, and that shirking has disastrous consequences for production and must be prevented. Then firms must pay at least $w$ to their workers.
} 
Assumptions (31) and (33) imply that consumers do not value liquidity at date 1 provided that they know that they will have a job at date 1 .

Continuation yields a private benefit $B$ to the entrepreneur, and a verifiable (pledgeable) income $X$. Assume $B+X>w$ so that continuation is optimal. ${ }^{24}$ As well, assume that

$$
\begin{gathered}
X-w<0, \\
x_{L}+X-w \geq 0,
\end{gathered}
$$

and

$$
-I+f_{H}\left(x_{H}+X-w\right) \geq 0 .
$$

With these parameter restrictions there is a feedback between aggregate liquidity and the maturity of savings such that multiple equilibria can arise.

- A long-maturity, high-liquidity, high-employment equilibrium.

Suppose, first, that all firms continue at date 1 in both states of nature. All

\footnotetext{
${ }^{24}$ In the notation of section $2, y=0$ or $w, B=b w^{2}-\left[w^{2} / 2\right]$. In section 2 , we assumed $X=0$. Here $X$ is assumed positive.
} 
consumers then have a job at date 1 and receive a wage $w$. By (31) and (33) they have no demand for liquidity and are thus willing to defer all payments on their date-0 investment to date 2 .

Since the corporate sector need not meet any short-term payment obligations, it always has enough liquidity to pay the date-1 wage $w$, as $x_{L}+X \geq w$ from (35). Conditions (35) and (36) then imply that the firms can repay date-0 investors out of $X$ since $-I+\left[f_{H} x_{H}+f_{L} x_{L}\right]+X-w \geq 0$. In this (efficient) equilibrium the corporate sector issues long-term claims and does not lay off workers.

- A short-maturity, low-liquidity, low-employment equilibrium.

Suppose instead that firms are unable to continue in the bad state of nature. Consumers become unemployed and because they have to to consume $\underline{c}_{1}$, they will insist on receiving at least $\underline{c}_{1}$ in this bad state of nature. Therefore, they want to hold short-term claims on firms. Condition (32) guarantees that this is indeed feasible, while (34) and (36) imply that given that workers are paid $\underline{c}_{1}$, firms no longer have any cash to finance the reinvestment. Firms continue only in the good state of nature, and equation (36) assures that such a plan can be financed at date 0 .

This (inefficient) equilibrium exhibits a coordination failure. ${ }^{25}$ It illustrates

\footnotetext{
${ }^{25}$ One might wonder whether this coordination failure could be avoided if workers invested
} 
in a stark manner that the liquidity available to the corporate sector depends on the liability side as well as the asset side. In this respect, it is interesting to note that a recent speech by the French finance minister ${ }^{26}$ called for "well-oriented savings," meaning a switch by households from short-term market investments towards long-term, equity investments that will benefit the productive sector. ${ }^{27}$

A couple of additional remarks can be made. First, the government can create aggregate liquidity by offering unemployment insurance. Unemployment insurance (above $\underline{c}_{1}$ ) here eliminates the consumers' demand for liquidity and restores the efficient equilibrium. Second, the multiplicity of equilibria could not arise in an Arrow-Debreu economy, because in a perfect capital market, firms would be able to pledge their entire date- 2 income which would be enough to pay workers at date 1 in both states.

solely in their own firm at date 0 and signed a contract with their employer specifying that no cash will be withdrawn at date 1 as long as they are not laid off. This arrangement is not robust to minor perturbations of the model such as job mobility or idiosyncratic liquidity shocks. Suppose for example that with a small probability each firm receives no income at all at date 1. Then the workers, who want to secure $\underline{c}_{1}$, must diversify their portfolio (have claims at least worth $\underline{c}_{1}$ in other firms), and the coordination failure may still occur. [Technically, one must assume that $x_{L}$ exceeds $\underline{c}_{1}$ slightly so as to offset the absence of income in this small number of firms and allow all consumers to "survive" in the bad state of nature.]

${ }^{26}$ Jean Arthuis' January 14, 1997 speech at the parliamentary meetings on savings.

${ }^{27}$ The speech discussed several ways of encouraging equity investments, such as the creation of pension funds and the reform of the tax system (equity investments in France are taxed at the personal income rate; this implies an overall tax rate of $61.7 \%$ for the highest tax bracket. In contrast, money market funds are taxed in a lump-sum fashion at a rate not exceeding $20 \%$ ). 


\subsection{Liquidity creation through price support policies: the example of commercial real estate.}

In many countries the recessions of the late 80 s and early 90 s have left the financial institutions burdened with depreciated commercial real estate. While banks, badly in need of liquidity, would have liked to divest their real estate holdings, they realized collectively that dumping real estate assets on the market simultaneously would have a disastrous impact on prices in a state of low demand for commercial real estate. In some countries (e.g., in France), cartel-like restraints on the disposition of real estate prevented prices from falling further. ${ }^{28}$ To an industrial organization observer, this behavior has all the attributes of a pricefixing case. This section argues that there is more to it than just collusion and that price stabilization may actually have helped to improve economic efficiency.

To illustrate the point, suppose that, as in section 6.1 , continuation at date 1 requires paying for an input, but this time, let the input be commercial real estate rather than labor. In case of continuation, one unit of commercial real estate is needed. The date-0 investment yields date- 1 income $x_{L}=0$ with probability $f_{L}$ and $x_{H}>0$ with probability $f_{H}=1-f_{L}$. As in section 2 , reinvestment yields a private benefit $B$ at date 2 , but no pledgeable income $(X=0$ in the notation

\footnotetext{
${ }^{28}$ Such cartels are sometimes organized by the Central Bank.
} 
of section 6.1). The reinvestment cost is $\rho+e$, where $\rho>0$ and $e$ is the price of commercial real estate. Letting $e_{L}$ and $e_{H}$ denote the commercial real estate prices in the bad and good states, the overall liquidity need is then

$$
\rho+e_{L} \quad \text { in the bad state (probability } f_{L} \text { ) }
$$

or

$$
\rho+e_{H}-x_{H}<0 \quad \text { in the good state (probability } f_{H} \text { ) }
$$

Commercial real estate construction is part of the initial invesment. Each firm buys one unit of real estate per unit of investment. Firms invest this amount in commercial real estate at date 0 because they want to stand ready to produce at least in the good state.

On the consumer side, we return to our basic paradigm in which preferences are linear: $c_{0}+c_{1}+c_{2}$.

Divested real estate is costlessly converted into residential real estate on a oneto-one basis, say. To make our main point in the starkest way, suppose that there is a fixed (residual) demand at price $v$; the absorption capacity of the residential real estate market is $z$. That is, if less than $z$ units of commercial real estate 
is converted, the price on the residential real estate market is $v$; if more than $z$ is converted, there is excess supply and the price on that market drops to 0 . Assume that

$$
v>(1-z)(\rho+v)
$$

Again, there are two possible equilibria:

- Low-price, low-production equilibrium:

Suppose that in the bad state the corporate sector dumps all its commercial real estate onto the residential market. The price drops to 0 , and since there is no other liquid asset besides real estate all firms are liquidated. Even though the commercial real estate is now free, firms are unable to continue.

- High-price, high-production equilibrium:

Suppose instead that only a fraction $\hat{z}$ of the assets are liquidated, where

$$
v=(1-\hat{z})(\rho+v)
$$

Conditions (37) and (38) imply that $\hat{z}<z$, and so the market price of real estate is $v$. The corporate sector thus has total available liquidity per unit of 
investment equal to $v$, and can finance the shortfall $\rho+v$ on a fraction $1-\hat{z}$ of its assets.

In this equilibrium, consumers pay higher date-1 prices for residential real estate and the restraint on sales provides insurance to the corporate sector against full credit rationing at date $1 .^{29}$ Such insurance raises ex ante social surplus.

\section{Concluding remarks}

For a long time, corporate finance has been treated as an appendix to asset pricing theory, with CAPM frequently used as the basic model for normative analyses of investment and financing decisions. While standard textbooks still reflect this tradition, the modern agency-theoretic literature is starting to influence the way corporate finance is taught. This paper takes the next logical step, which is to suggest that if financing and investment decisions reflect agency problems — as seems to be widely accepted - then it is likely that modern corporate finance will require adjustments in asset pricing theories, too.

Our paper is a very preliminary effort to analyze this reverse influence of corporate finance on asset pricing. We have employed a standard agency model

\footnotetext{
${ }^{29}$ This example is in the spirit of Kiyotaki and Moore's 1997 analysis of the dual role of certain assets as a store of value and an input into production. Our emphasis differs both in the ingredients (our treatment relies on the existence of aggregate shocks while theirs does not) and in the emphasis (they stress the possibility of business cycles while we emphasize market power and liquidity creation through price support policies.).
} 
in which part of the returns from a firm's investment cannot be pledged to outsiders, raising a demand for long-term financing, that is, for liquidity. We have also assumed that individuals cannot pledge any of their future income, so that borrowing against human capital is impossible. As a result, the economy is typically capital constrained, implying that collateralizable assets are in short supply. Such assets will command a premium, which is determined by the covariation of the asset's return with the marginal value of liquidity in different states. Risk neutral firms are willing to pay a premium on assets that help them in states of liquidity shortage. This is a form of risk aversion, but unlike in models based on consumer risk aversion, return variation within states that experience no liquidity shortage is inconsequential for prices. Thus, liquidity premia have a built-in skew.

One consequence of this skew is that price volatility tends to be higher in states of liquidity shortage, as we illustrated in Section 3. Another consequence is that long-term bonds, because of a higher price risk, tend to sell at a discount relative to short-term bonds as we showed in Section 4. This may be one reason why the yield curve most of the time is upward sloping, a feature that does not readily come out of a complete market model.

The price dynamics in our model satisfy standard Euler conditions — in par- 
ticular, prices follow a martingale as long as there is no readjustment in the corporate sector's coordinated investment plan. It is an interesting possibility that marginal rates of substitution for the corporate sector may be quite different, and perhaps more volatile in the short run, than the marginal rates of substitution of a representative consumer. This could help to resolve some of the empirical difficulties experienced with consumption-based asset pricing models, which appear to feature too little variation in MRSs.

Our model is quite special in that asset prices are entirely driven by a corporate demand for liquidity; consumers hold no bonds or other assets that sell at a premium. It has been suggested to us that once the model is changed so that consumers also have a liquidity demand, MRSs of consumers and firms will be equalized, and we are back to the old problem with excess asset price volatility. However, if consumers participate selectively in asset markets, then the MRSs of the relevant sub-population may have high volatility and yet be hard to detect. In this case, the equality between consumer and producer MRSs can be exploited in the reverse: by evaluating corporate MRSs, we can infer what the MRS of the representative consumer in the sub-population is. This may be a useful empirical strategy if firm data are more readily available and easier to analyze than consumer data. 
Finally, we note that violations of the martingale condition, as illustrated by the end-of-period drop in the liquidity premium, may help to explain the wellknown paradox that prices of long-term bonds tend to move up rather than down, following a period in which the yield spread (long/short) is exceptionally high. This finding is very difficult to reconcile with the standard expectations theory (Campbell, 1995), but could perhaps be accounted for in a theory where liquidity demand shifts between short and long instruments in response to changes in liquidity needs. 


\section{References}

Aiyagari, R., and M. Gertler (1991) “Asset Returns with Transaction Costs and Uninsured Individual Risk," Journal of Monetary Economics, 27: 311-331.

Black, F. (1976) "Studies of Stock Price Volatility Changes," Proceedings of the American Statistical Association, Business and Statistics Section, 177-181.

Blanchard, O. (1993) "Movements in the Equity Premium," Brookings Papers on Economic Activity, 2:75-138.

Bollerslev, T., Chou, R. and K. Kroner (1992) "ARCH Modeling in Finance," Journal of Econometrics, 52: 5-59.

Breeden, D.T. (1979) "An Intertemporal Asset Pricing Model with Stochastic Consumption and Investment Opportunities," Journal of Financial Economics, 7:265-96.

Calomiris, C. (1989) "The Motivation for Loan Commitments Backing Commercial Paper," Journal of Banking and Finance, 13: 271-278.

Campbell, J. (1995) "Some Lessons from the Yield Curve," Journal of Economic Perspectives, 9:129-152.

Campbell, J., and R. Shiller (1993) "Yield Spreads and Interest Rate Movements: A Bird's Eye View," Review of Economic Studies, 58: 495-514.

Campbell, J., Lo, A., and C. MacKinlay (1996) The Econometrics of Financial 
Markets, Princeton: Princeton University Press.

Cox, J., Ingersoll, J., and S. Ross (1985) "A Theory of the Term Structure of Interest Rates," Econometrica, 53: 385-407.

Crane, D. (1973) "Managing Credit lines and Commitments," study prepared for the Trustees of the Banking Research Fund Association of Reserve City Bankers, Graduate School of Business Administration, Harvard University.

Culbertson, J. (1957) "The Term Structure of Interest Rates," Quarterly Journal of Economics, 71: 485-517.

Diamond, D., and P. Dybvig (1983) "Bank Runs, Deposit Insurance, and Liquidity," Journal of Political Economy, 91: 401-19.

Engle, R., Ng, V., and M. Rothschild (1990) “Asset Pricing with a FactorArch Covariance Structure," Journal of Econometrics, 45: 213-237.

Fama, E. (1965) “The Behavior of Stock Market Prices," Journal of Business, 38: 34-105.

Ferson, V. (1995) "Theory and Empirical Testing of Asset Pricing Models," in Handbooks in Organizational Research and Management Science, R. Jarrow et al. eds., 9:145-200.

Froot, K., Scharfstein, D., and J. Stein (1993) "Risk Management: Coordinating Investment and Financing Policies," Journal of Finance, 48: 1629-1658. 
Ghysels, E., Harvey, A., and E. Renault (1996) "Stochastic Volatilily," in Handbook of Statistics, Vol. 14, ed. by G. Maddala and C. Rao, North Holland.

Gorton, G. and G. Pennacchi (1993) "Security Baskets and Indexed-Linked Securities," Journal of Business, January.

Hansen, L., and R. Jagannathan (1991) "Implications of Security Market Data for Models of Dynamic Economies," Journal of Political Economy, 99: 225-262.

Harrington, R. (1987) "Asset and Liability Management by Banks," OECD. Harrison, J., and D.M. Kreps (1979) "Martingales and Arbitrage in Multiperiod Securities Markets," Journal of Economic Theory, 20: 381-408.

Hicks, J. (1967) Critical Essays in Monetary Theory, Oxford: Oxford University Press.

Hirshleifer, J. (1971) "The Private and Social Value of Information and the Reward to Inventive Activity," American Economic Review, 61: 561-574.

Holmström B. and J. Tirole (1998) "Private and Public Supply of Liquidity," Journal of Political Economy, 106: 1-40.

_ (1996) "Modelling Aggregate Liquidity," American Economic Review, Papers and Proceedings, 86(2): 187-191.

Jacklin, C. (1987) "Demand Deposits, Trading Restrictions, and Risk Sharing," in Contractual Arrangements for Intertemporal Trade, edited by E. Prescott 
and N. Wallace, Minneapolis: University of Minnesota Press.

Keynes, J.M. (1930) "A Treatise on Money," in Collected Writings of J.M. Keynes, ed. D.E. Moggridge, London: Macmillan 1973.

Kiyotaki, N. and J. Moore (1997) "Credit Cycles," Journal of Political Economy, 105: 211-248.

Leland, H. (1997) "Corporate Risk Management: Promises and Pitfalls," annual IDEI-Region Midi-Pyrnes lecture.

Lintner, J. (1965) "The Valuation of Risk Assets and the Selection of Risky Investments in Stock Portfolios and Capital Budgets," Review of Economics and Statistics, 4\%: 13-37.

Lucas, R. E., Jr. (1978) "Asset Prices in an Exchange Economy," Econometrica 46: 1429-45.

Malkiel, B. (1992) "Term Structure of Interest Rates," in The New Palgrave Dictionary of Money and Finance, edited by P. Newman, M. Milgate and J. Eatwell, vol. 3: 650-52.

Mandelbrot, B. (1963) “The Variation of Certain Speculative Prices," Journal of Business, 36: 394-419.

Mehra, R., and E.C. Prescott (1985) "The Equity Premium: A Puzzle," Journal of Monetary Economics, 15: 145-61. 
Modigliani, F. and R. Sutch (1966) "Innovations in Interest Rate Policy," American Economic Review, Papers and Proceedings, 56: 178-97.

Mossin, J. (1966) "Equilibrium in a Capital Asset Market," Econometrica, 35: $768-783$.

Rubinstein, M. (1976) “The Valuation of Uncertain Income Streams and the Pricing of Options," Bell Journal of Economics, 7: 407-425.

Schiller, R. (1989) Market Volatility, Cambridge: MIT Press.

Sharpe, W.F. (1964) "Capital Asset Prices: A Theory of Market Equilibrium under Conditions of Risk," Journal of Finance, 19: 425-442.

Stein, J. (1996) "An Adverse Selection Model of Bank Asset and Liability Management with Implications for the Transmission of Monetary Policy," mimeo, MIT.

Stigum, M. (1990) The Money Market, 3rd edition. Irwin, Burr Ridge, Illinois. Subrahmanyam, A. (1991) "A Theory of Trading in Stock Index Futures," Review of Financial Studies.

Vissing-Jorgensen, A. (1997) "Limited Stock Market Participation," Mimeo, Department of Economics, MIT.

Weil, P. (1989) “The Equity Premium Puzzle and the Risk-Free Rate Puzzle," Journal of Monetary Economics, 24: 401-421. 
Williams, W. (1988) "Asset Liability Management Techniques". 


\section{Appendix: Treatment of the productive sector as an aggregate}

Suppose that there are $n$ firms, $i=1, \ldots, n$, each run by an entrepreneur, say. Firm $i$ starts with initial wealth $A_{i}$ and invests $I_{i}$, so that the net outlay for investors is $N_{i}\left(I_{i}\right)=I_{i}-A_{i}$. At date 1 , in state $\omega$, firm $i$ takes a decision $d_{i}(\omega)$ in a subset $D_{i}\left(\omega, L_{i}^{n}(\omega)\right)$ of the technologically feasible set $D_{i}$, where $L_{i}^{n}(\omega) \gtrless 0$ is the net liquidity available to firm $i$ in state $\omega . \quad L_{i}^{n}(\omega)>0$ means that firm $i$ uses liquidity, and $L_{i}^{n}(\omega)<0$ means that firm $i$ supplies liquidity in state $\omega$. The decision $d_{i}(\omega)$ generates an expected pledgeable income from productive assets $r_{i}\left(I_{i}, \omega, d_{i}(\omega)\right)$ and a total expected income from productive assets $R_{i}\left(I_{i}, \omega, d_{i}(\omega)\right)$. Let

$$
B_{i}\left(I_{i}, \omega, d_{i}(\omega)\right) \equiv R_{i}\left(I_{i}, \omega, d_{i}(\omega)\right)-r_{i}\left(I_{i}, \omega, d_{i}(\omega)\right)
$$

denote the nonpledgeable income of firm $i$ that must go to entrepreneur $i$. Entrepreneur $i$ may, however, be paid more than $B_{i}$. Let $t_{i}(\omega) \geq 0$ denote the expected transfer on top of the nonpledgeable income $B_{i} . \quad\left(t_{i}(\cdot)\right.$ could without loss of generality be chosen equal to 0 in the example.) So entrepreneur $i$ obtains, in state $\omega, B_{i}\left(I_{i}, \omega, d_{i}(\omega)\right)+t_{i}(\omega)$. If firm $i$ withdraws gross liquidity $t_{i}(\omega)$ from noncorporate assets, then the net liquidity available to the firm is $L_{i}^{n}(\omega)=L_{i}(\omega)-t_{i}(\omega)$. 
The economically feasible set for firm $i$ reflects the fact that no investor wants to enter negative NPV investments at date 1:

$$
D_{i}\left(\omega, L_{i}(\omega)-t_{i}(\omega)\right)=\left\{d_{i} \in D_{i} \mid r_{i}\left(I_{i}, \omega, d_{i}(\omega)\right)-t_{i}(\omega)+L_{i}(\omega) \geq 0\right\} .
$$

Let

$$
D\left(\omega, L^{n}(\omega)\right) \equiv\left\{\times_{i=1}^{n} D_{i}\left(\omega, L_{i}^{n}(\omega)\right) \mid \sum_{i=1}^{n} L_{i}^{n}(\omega) \leq L^{n}(\omega)\right\}
$$

denote the product decision set, with generic element $d(\omega)$. Consider a coordinated plan with weights $\left\{w_{i}\right\}_{i=1, \ldots, n}$ defined as the solution to the following

\section{Program $I$}

$$
\max _{\{I, L ., d(\cdot), t(\cdot)\}}\left\{E_{0}\left[\sum_{i} w_{i}\left[B_{i}\left(I_{i}, \omega, d_{i}(\omega)\right)+t_{i}(\omega)-A_{i}\right]\right]\right\}
$$

s.t.

$$
E_{0}\left[\sum_{i} r_{i}\left(I_{i}, \omega, d_{i}(\omega)\right)\right] \geq \sum_{i}\left[I_{i}-A_{i}\right]+\sum_{k}\left(q_{k}-1\right) L_{k}
$$

and 


$$
d(\omega) \in D\left(\omega, \sum_{k} \theta_{k}(\omega) L_{k}-\sum_{i} t_{i}(\omega)\right)
$$

Letting $\mu$ denote the multiplier of the break-even constraint, optimization with respect to $L_{k}$, together with the equilibrium condition $L_{k}=\bar{L}_{k}$ yields

$$
q_{k}-1=E_{0}\left[m(\omega) \theta_{k}(\omega)\right]
$$

where

$$
m(\omega)=\left.\frac{d}{d L}\left[\max _{d \in D(\omega, L)}\left\{\frac{\sum_{i} w_{i} B_{i}+\mu\left(\sum_{i} r_{i}\right)}{\mu}\right\}\right]\right|_{L=\sum_{k} \theta_{k}(\omega) \bar{L}_{k}-\sum_{i} t_{i}(\omega)} .
$$

as in equation (9). The first-order condition with respect to $t_{i}(\omega)$ is:

is:

$$
\begin{array}{llll}
\text { either } & t_{i}(\omega)=0 \quad \text { and } & w_{i} \leq \mu[1+m(\omega)] \\
\text { or } & t_{i}(\omega)>0 \quad \text { and } & w_{i}=\mu[1+m(\omega)]
\end{array}
$$

Now assume that there exists at least one state of nature with excess liquidity (this is the case in all our examples). Then for all $i, t_{i}(\omega)=0$ whenever $m(\omega)>$ 
0. That is, pledgeable income is never distributed to entrepreneurs in states of liquidity shortage. The marginal liquidity service can then be rewritten as:

$$
m(\omega)=\left.\frac{d}{d L}\left[\max _{d \in D(\omega, L)}\left\{\frac{\sum_{i} w_{i} B_{i}+\mu\left(\sum_{i} r_{i}\right)}{\mu}\right\}\right]\right|_{L=\sum \theta_{k}(\omega) \bar{L}_{k}}
$$

Thus the equilibrium is as described in the text, with $B \equiv \sum_{i} w_{i} B_{i}$, and $r \equiv$ $\sum_{i} r_{i}$

Remark: In Program I, we did not consider individual rationality constraints for the entrepreneurs because such constraints only affect the set of feasible weights $w_{i}$

Let us now show that a decentralized equilibrium of a market for statecontingent liquidity can be construed as an optimal coordinated plan. Suppose that the firms at date 0 contract on their date- 1 , state-contingent liquidity in a perfect market. Let $m(\omega)$ denote the net cost of one unit of liquidity in state $\omega$. That is, in order to receive $L_{i}(\omega)$ in state $\omega$, for all $\omega$, firm $i$ must pay $E_{0}\left[(1+m(\omega)) L_{i}(\omega)\right]$ at date 0 . Firm $i$ therefore solves:

$$
\max _{\left\{I_{i}, L_{i}(\cdot), d_{i}(\cdot), t_{i}(\cdot)\right\}}\left\{E_{0}\left[B_{i}\left(I_{i}, \omega, d_{i}(\omega)\right)+t_{i}(\omega)-A_{i}\right]\right\}
$$

s.t. 


$$
E_{0}\left[r_{i}\left(I_{i}, \omega, d_{i}(\omega)\right)-t_{i}(\omega)\right] \geq I_{i}-A_{i}+E_{0}\left[m(\omega) L_{i}(\omega)\right]
$$

and

$$
d_{i}(\omega) \in D_{i}\left(\omega, L_{i}(\omega)-t_{i}(\omega)\right)
$$

Letting $1 / w_{i}$ denote the shadow price of the budget constraint, this program, under our concavity assumptions, is equivalent to

\section{Program II}

$$
\begin{aligned}
\max _{\left\{I_{i}, L_{i}(\cdot), d_{i}(\cdot), t_{i}(\cdot)\right\}}\left\{E _ { 0 } \left[w_{i}\left[B_{i}\left(I_{i}, \omega, d_{i}(\omega)\right)+t_{i}(\omega)\right]\right.\right. \\
\left.\left.+r_{i}\left(I_{i}, \omega, d_{i}(\omega)\right)-t_{i}(\omega)-I_{i}-m(\omega) L_{i}(\omega)\right]\right\}
\end{aligned}
$$

s.t.

$$
d_{i}(\omega) \in D_{i}\left(\omega, L_{i}(\omega)-t_{i}(\omega)\right) \quad \text { for all } \omega
$$

Given the existence of a state $\omega_{0}$ such that $m\left(\omega_{0}\right)=0$, optimizing over $t_{i}(\omega)$ and 
$L_{i}(\omega)$ implies that $w_{i} \leq 1$ for all $i$, and $t_{i}(\omega)=0$ for all $\omega$ if $w_{i}<1$.

Summing over the individual programs, we see that the market equilibrium solves

$$
\max E_{0}\left[\sum_{i} w_{i}\left[B_{i}+t_{i}\right]+\sum_{i}\left[r_{i}-r_{t}\right]-m(\omega) \sum_{i} L_{i}\right]
$$

s.t.

$$
d_{i}(\omega) \in D_{i}\left(\omega, L_{i}(\omega)-t_{i}(\omega)\right) \quad \text { for all } \omega
$$

From our previous characterization,

$$
\sum_{i}\left(w_{i}-1\right) t_{i}(\omega)=0 \quad \text { for all } \omega
$$

which implies that the constraints $d_{i} \in D_{i}$ can be replaced by $d \in D$, as defined earlier. Therefore the market equilibrium solves Program I for some weights $\left\{w_{i}\right\}$

Remarks:

1. This equivalence result would not hold, necessarily, if the set of liquid instruments did not span the state-contingent claim space. In this sense, we 
are assuming that the state-contingent liquidity space is complete.

2. The weights $\left\{w_{i}\right\}$ are endogenous, so one cannot conduct comparative statics exercises with this representation, and we do not. However, the analysis of price dynamics in Section 4 is valid, because it entails no rebalancing of portfolios. 


\begin{tabular}{lll} 
Date 0 & Date 1 & Date 2 \\
\hline \multirow{4}{*}{ Set up cost $I$ and choice } & & - Random income $x$. \\
of liquidity $L$. Investors & Total income is $x+L$. & Private benefit \\
disburse $I+q L$. & - Reinvestment $y(x)$. & by $y^{2} / 2$ for the \\
& - Payout to investors & \\
& $x+L-y(x)$.
\end{tabular}

Figure 1

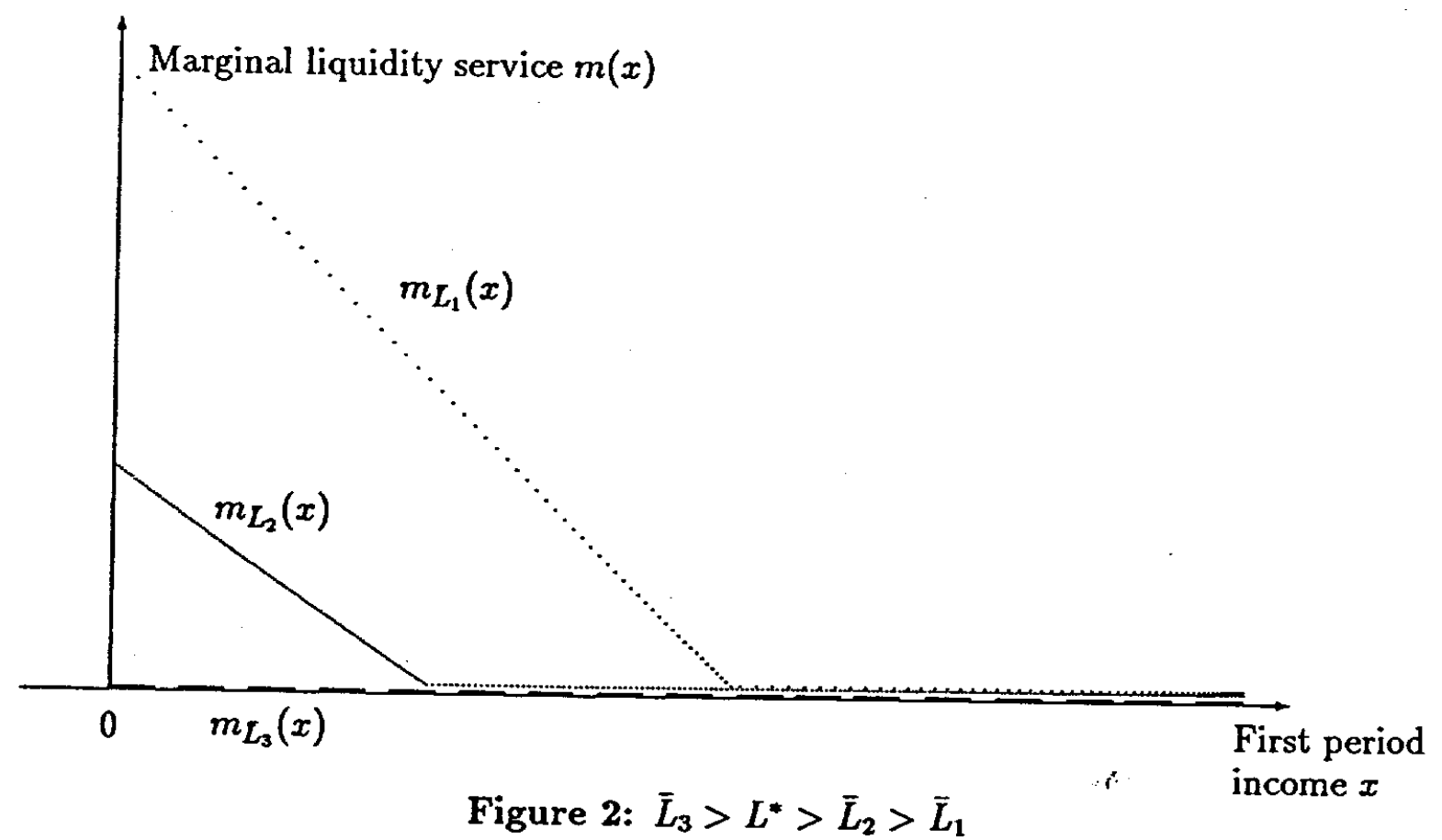

